\title{
Consumo de forragem por ovinos ingerindo grama missioneira gigante com ou sem acesso a amendoim forrageiro
}

[Herbage intake by lambs grazing missioneira gigante grass with or without access to peanut pastures]

\author{
J.G. Dal-Pizzol'1, R. Biasiolo ${ }^{1}$, G.T. Raupp ${ }^{1}$, J.N.C. Baldissera ${ }^{1}$, E.X. Almeida ${ }^{2}$, \\ H.M.N. Ribeiro Filho ${ }^{1 *}$ \\ 1Universidade do Estado de Santa Catarina - Lages, SC \\ ${ }^{2}$ Empresa de Pesquisa Agropecuária do Estado de Santa Catarina - Ituporanga, SC
} J.G. Dal-Pizzol ${ }^{1}$ https://orcid.org/0000-0003-3063-2220 R. Biasiolo ${ }^{1}$ https://orcid.org/0000-0001-6349-784 G.T. Raupp ${ }^{1}$ https://orcid.org/0000-0003-0147-3160 J.N.C. Baldissera ${ }^{1}$ https://orcid.org/0000-0002-7905-7717 E.X. Almeida ${ }^{2}$,
https://orcid.org/0000-0002-3480-3392 H.M.N. Ribeiro Filho

RESUMO

A grama missioneira gigante (Axonopus catharinensis Valls) é uma espécie forrageira que merece ser melhor investigada tanto pura como recebendo a inclusão de leguminosas. Objetivou-se avaliar o consumo de MS por ovinos pastejando grama missioneira gigante com ou sem acesso a pastos de amendoim forrageiro (Arachis pintoi cv. Amarillo). Para isso, foi conduzido um experimento prévio com cordeiros alojados em gaiolas metabólicas, gerando-se uma equação para a estimativa do consumo tomando como base a excreção fecal de proteína bruta (PBf), que apresentou $\mathrm{R}^{2}=0,91$. Em um segundo experimento, foi avaliado o consumo de forragem por ovinos em pastos de grama missioneira gigante com duas alturas de entrada ( 25 ou $35 \mathrm{~cm}$ ), com ou sem acesso a áreas de amendoim forrageiro por duas horas diárias. A altura de entrada na grama missioneira gigante não alterou o consumo total de MS, mas o acesso aos piquetes da leguminosa aumentou o consumo em aproximadamente $20 \%$. Em conclusão, a grama missioneira gigante pode ser manejada com alturas de entrada entre 25 e $35 \mathrm{~cm}$, enquanto o acesso a áreas de amendoim forrageiro por duas horas diárias aumenta o consumo de MO por cordeiros pastejando a missioneira.

Palavras-chave: Arachis pintoi cv. Amarillo, Axonopus catharinensis Valls, índices fecais, consumo de forragem

\begin{abstract}
The missioneira gigante grass (Axonopus catharinensis Valls) is a grass that deserves to be better investigated both pure and receiving the inclusion of legumes. The objective of this work was to evaluate the herbage intake by sheep grazing missioneira gigante grass with or without access to peanut grass (Arachis pintoi cv. Amarillo). A previous experiment was conducted using lambs housed in metabolic cages, generating an equation for estimation of herbage intake as a function of faecal crude protein excretion $(C P f)$. The equation presented a value of $R^{2}=0.91$. In the grazing experiment, the herbage intake was evaluated using missioneira gigante pastures with two pre-grazing sward heights 25 or $35 \mathrm{~cm}$ ), with or without access to peanut areas during two hours per day. The pre-grazing sward height of missioneira gigante did not change the total OM herbage intake, but the access to peanut pastures increased the herbage intake by approximately $20 \%$. In conclusion, missioneira gigante grass has shown flexibility to be used with pre-grazing sward heights between 25 and $35 \mathrm{~cm}$, while the access to forage peanut pastures during two hours daily increases herbage OM intake by lambs grazing grass.
\end{abstract}

Keywords: Axonopus catharinensis, faecal index, forage intake

Recebido em 6 de dezembro de 2017

Aceito em 23 de maio de 2018

*Autor para correspondência ( corresponding author)

E-mail: henrique.ribeiro@udesc.br 


\section{INTRODUÇÃO}

O uso da forragem pastejada em sistemas de produção de ruminantes se destaca por reduzir a necessidade de mão de obra e o custo da alimentação. Em regiões de clima tropical e subtropical, as pastagens são formadas, em sua maioria, por gramíneas perenes estivais, as quais normalmente apresentam produções satisfatórias de matéria seca, mas valor alimentar limitado e amplamente afetado pelo aumento da idade de rebrota (Waramit et al., 2012). Além dissso, a produtividade primária das gramíneas estivais é altamente dependente de nitrogênio, sendo a inclusão de leguminosas no sistema uma ferramenta para obtenção de vantagens adicionais, tanto do ponto de vista econômico, como nutricional, zootécnico e ambiental.

As leguminosas aumentam o aporte de nitrogênio no solo, disponibilizando-o, assim, para as gramíneas presentes, o que reduz a necessidade de uso de fertilizantes nitrogenados (Barbero et al., 2009). Além disso, possuem melhor valor alimentar e, quando adicionadas à dieta, aumentam o consumo (Ribeiro-Filho et al., 2003) e melhoram a digestibilidade de gramíneas de baixa qualidade devido ao maior aporte de proteína bruta (Niderkorn e Baumont, 2009). Entre as leguminosas de clima tropical, o amendoim forrageiro (Arachis pintoi) tem se destacado pelo valor nutritivo, mas também por ser resistente a períodos de estiagem e ao pastoreio, além de aumentar o consumo voluntário (Schnaider et al., 2014) e o desempenho (Andrade et al., 2016), quando incluído na dieta de animais alimentando-se de capim-elefante anão (Pennisetum purpureum Schum). De outra forma, o impacto da inclusão dessa leguminosa em dietas à base de espécies de gramíneas menos estudadas, como a grama missioneira gigante (Axonopus catharinensis Valls), ainda merece ser melhor investigado.

A grama missioneira gigante é uma gramínea perene de clima tropical, que apresenta alto potencial de produção de matéria seca, resistência ao pisoteio, ao sombreamento e ao frio. Por se tratar de uma espécie que surgiu há poucos anos (Tcacenco e Soprano, 1997), o número de publicações relativas a ela ainda é baixo, o que justifica a condução de trabalhos visando recomendações de manejo que otimizem o consumo diário de forragem e, consequentemente, o desempenho animal.

Entretanto, a estimativa acurada do consumo de forragem por animais em pasto depende do uso de técnicas que devem preferencialmente ter sido precedidas de alguma validação local (Carvalho et al., 2007). Entre essas, destaca-se o uso de indicadores de índices fecais (Boval et al., 1996; Carvalho et al., 2007), os quais podem ser de grande valia desde que sejam construídas equações específicas para cada situação, como demonstrado por Kozloski et al. (2014).

Este trabalho foi desenvolvido com o objetivo de avaliar se a altura ou a inclusão do amendoim afeta o consumo total de matéria seca por cordeiros em pastos de grama missioneira gigante pura em diferentes alturas de entrada, com ou sem acesso a piquetes de amendoim forrageiro por duas horas por dia. Testou-se a hipótese de que o consumo de forragem é reduzido com o aumento na idade de rebrota (maior altura) da grama missioneira, mas o acesso à leguminosa aumenta o consumo independentemente da idade de rebrota da gramínea.

\section{MATERIAL E MÉTODOS}

Todos os procedimentos utilizados neste trabalho foram avaliados pelo Comitê de Ética em Experimentação Animal da UDESC (Cetea/UDESC) e aprovados em seus aspectos éticos e metodológicos, sob o número de protocolo 01.11.14.

Foram conduzidos dois experimentos na Estação Experimental da Epagri, no município de Ituporanga SC, Brasil, coordenadas geográficas $27^{\circ} 38^{\prime} \mathrm{S}, 4^{\circ} 60^{\prime} \mathrm{O}$. O clima da região é classificado, segundo Köeppen, como tipo Cfa (subtropical úmido), com temperatura média de $17^{\circ} \mathrm{C}$ e precipitação anual média total de $1500 \mathrm{~mm}$. O solo da área é do tipo cambissolo álico. Dados meteorológicos mensais referentes ao período de realização dos experimentos estão presentes da Tab. 1. 
Tabela 1. Dados meteorológicos mensais referentes ao período de realização dos experimentos

\begin{tabular}{ccccc}
\multirow{2}{*}{ Mês/ano } & \multirow{2}{*}{ Pluviometria $(\mathrm{mm})$} & \multicolumn{3}{c}{ Temperatura $\left({ }^{\circ} \mathrm{C}\right)$} \\
\cline { 3 - 5 } & & Mínima & Média & Máxima \\
\hline $11 / 13$ & 190 & 15,7 & 20,4 & 26,3 \\
$12 / 13$ & 224 & 17,8 & 22,8 & 29,5 \\
$01 / 14$ & 157 & 17,4 & 23,9 & 31,6 \\
$02 / 14$ & 172 & 18,7 & 24,4 & 32,1 \\
$03 / 14$ & 56 & 18,0 & 21,6 & 28,1 \\
$04 / 14$ & 13,7 & 18,9 & 24,9 \\
\hline
\end{tabular}

O primeiro experimento teve como objetivo gerar uma equação para a estimativa de consumo de forragem com base na excreção fecal diária de proteína em ovinos ingerindo grama missioneira gigante com acesso a amendoim forrageiro por $2 \mathrm{~h} /$ dia. O trabalho foi conduzido nos meses de janeiro a abril de 2014, utilizando-se oito ovinos machos, castrados, da raça Ile de France, com idade média de seis meses e peso médio inicial de $35,8 \pm 4,2 \mathrm{~kg}$, alojados em gaiolas metabólicas. A idade média de rebrote dos pastos foi de 35 dias. Para isso, semanalmente, uma área correspondente à quantidade de forragem necessária para o consumo de uma semana era cortada e utilizada no intervalo entre 33 e 37 dias de rebrota. Após cada corte, foi realizada a aplicação de $60 \mathrm{~kg} \mathrm{~N} / \mathrm{ha}$, na forma de ureia.

O consumo voluntário de forragem e a proporção de amendoim forrageiro na dieta total foram definidos em período preliminar. $\mathrm{O}$ amendoim forrageiro foi fornecido ad libitum por $2 \mathrm{~h} / \mathrm{dia}$ (das oito às 10 horas), e a grama missioneira gigante ad libitum no restante do tempo (10 às oito horas do dia seguinte). $\mathrm{O}$ consumo voluntário médio foi de aproximadamente 3,5\% do PV e a proporção de amendoim forrageiro na MS total consumida foi de aproximadamente $25 \%$ do total consumido.

Com base nos resultados preliminares, foram estipulados quatro níveis de oferecimento de forragem: ad libitum: $3 \% \mathrm{PV} ; 2,5 \% \mathrm{PV}$ e $2 \%$ PV. O experimento foi conduzido em um delineamento experimental em duplo quadrado latino, com quatro períodos de 15 dias (10 de adaptação e cinco de avaliação). $\mathrm{O}$ fornecimento ad libitum foi estabelecido por meio do acréscimo no fornecimento em $20 \%$ ao consumo do dia anterior, sendo esse valor calculado diariamente antes da primeira refeição. Nas dietas em que o oferecimento foi restrito, a proporção de amendoim foi fixada em $25 \%$ da MS total, o qual foi oferecido às oito horas. Duas horas após o fornecimento do amendoim, era realizada a limpeza dos cochos para pesagem e amostragem das sobras, quando havia. Em seguida, era fornecida a grama missioneira gigante, duas vezes ao dia (às oito e às 17 horas).

O segundo experimento foi conduzido em arranjo fatorial $2 \times 2$, sendo os fatores a altura de entrada no piquete de grama missioneira $(25 \mathrm{e}$ $35 \mathrm{~cm}$ ) e o acesso ou não a pastos de amendoim forrageiro por duas horas por dia. $\mathrm{O}$ experimento foi conduzido de fevereiro a março de 2014. Foram utilizados 24 ovinos machos, castrados, com idade média de seis meses e peso vivo médio inicial de $28,4 \pm 4,7 \mathrm{~kg}$. Os animais foram divididos em quatro grupos de seis animais. Foram utilizadas duas áreas, uma com grama missioneira gigante $(0,64 \mathrm{ha})$, subdividida em 16 piquetes, e outra com amendoim forrageiro (0,1ha), também subdivida em 16 piquetes. Antes do início do experimento, a área de missioneira foi adubada com dejeto líquido de suíno na proporção de $50 \mathrm{~m}^{3} / \mathrm{ha}$, e realizou-se uma roçada em dois dos piquetes, com o objetivo de criar os contrastes de altura inerentes entre os tratamentos. A cada semana subsequente, mais dois piquetes eram roçados com o mesmo objetivo. As alturas pré e pós-pastejo foram medidas com bastão graduado ("sward stick") a partir de 50 medidas por piquete. A altura de saída foi definida como $50 \%$ da altura de entrada. Antes do período de avaliação, os animais foram adaptados aos tratamentos por 21 dias e pesados antes e após o período de avaliação.

O consumo total de matéria seca foi estimado por meio da equação gerada no experimento 1 . Para isso, foi necessária a realização de coleta total de fezes de todos os animais, sendo esta realizada 
nos últimos cinco dias do período de avaliação. Para a coleta, foram utilizados arreios coletores, que eram esvaziados duas vezes ao dia, de manhã e no final da tarde. Logo após a coleta, o total de fezes produzidas por animal era pesado e uma amostra era coletada, perfazendo um total de 10 amostras por animal. As amostras de fezes eram levadas para estufa com ventilação forçada, a uma temperatura de $60^{\circ} \mathrm{C}$, por 72 horas, e moídas para posteriores análises. As amostras de cada animal foram agrupadas formando uma amostra composta por animal. Devido ao curto prazo do período de avaliação, os dados de desempenho não foram considerados.

Os teores de MS foram determinados por secagem em estufa a $105^{\circ} \mathrm{C}$ por 24 horas. Os teores de $\mathrm{MM}$ e $\mathrm{MO}$ foram quantificados por incineração em forno mufla, a $550^{\circ} \mathrm{C}$ por quatro horas (Afnor, 1985). A dosagem de proteína bruta foi realizada pela técnica de Kjeldahl (Official..., 1995). Os teores de FDN e FDA foram analisados pelo método de Van Soest et al. (1991), utilizando-se equipamento Fiber Analyzer (Ankom Technology Corporation, Fairport, NY, USA).

Para a obtenção da equação de estimativa de consumo de $\mathrm{MO}$ em pasto, foi gerada uma equação em que o consumo de MO foi considerado a variável dependente e a excreção fecal diária de proteína, a variável independente. A relação entre o consumo diário de $\mathrm{MO}$ e a excreção diária de proteína nas fezes foi analisada por meio de regressão linear, utilizando-se o PROC GLM do pacote estatístico SAS (SAS..., 2004).

Para a análise estatística do segundo experimento, foi utilizado o procedimento PROC GLM do pacote estatístico SAS (SAS..., 2004), sendo utilizado um modelo linear considerando os efeitos fixos da altura da missioneira, do acesso ou não ao amendoim forrageiro e a interação entre estes.

\section{RESULTADOS}

Os teores de proteína bruta variaram de 111 a $141 \mathrm{~g} / \mathrm{kg}$ MS na grama missioneira gigante e de 185 a $213 \mathrm{~g} / \mathrm{kg}$ MS no amendoim forrageiro, enquanto os teores de FDN variaram de 646 a 598 na missioneira e de 459 a 376 no amendoim, quando considerados os experimentos 1 e 2 , respectivamente (Tab. 2).

O consumo observado de MO foi altamente correlacionado $\left(\mathrm{R}^{2}=0,91\right)$ com a excreção fecal diária de proteína bruta (PBf), observando-se que cada grama a mais de $\mathrm{PBf}$ representou aumento de $20,9 \mathrm{~g} /$ dia de MO ingerida (Fig. 1). Não houve efeito da interação entre a altura da grama missioneira gigante e o acesso à leguminosa para nenhuma das variáveis analisadas (Tab. 3). O consumo de MO não foi afetado pela idade de rebrota da grama missioneira, mas foi aproximadamente $20 \%$ superior $(\mathrm{P}<0,05)$ nos cordeiros que tiveram acesso aos piquetes de amendoim forrageiro em comparação aos que não tiveram acesso à leguminosa.

Tabela 2. Composição química (g/kg MS) média dos alimentos ingeridos, obtidos pela diferença entre o alimento fornecido e as sobras no experimento 1, e por simulação de pastejo no experimento 2, durante os meses de janeiro a abril de 2014, em Ituporanga, SC

\begin{tabular}{ccccc} 
& \multicolumn{2}{c}{ Experimento 1 } & \multicolumn{2}{c}{ Experimento 2 } \\
\cline { 2 - 5 } & Missioneira & Amendoim & Missioneira & Amendoim \\
\hline Matéria seca (g/kg verde) & 226 & 224 & 245 & 254 \\
Matéria orgânica & 918 & 915 & 923 & 919 \\
Proteína bruta & 111 & 185 & 141 & 213 \\
Fibra em detergente neutro & 646 & 459 & 598 & 376 \\
Fibra em detergente ácido & 298 & 288 & 265 & 200 \\
\hline
\end{tabular}




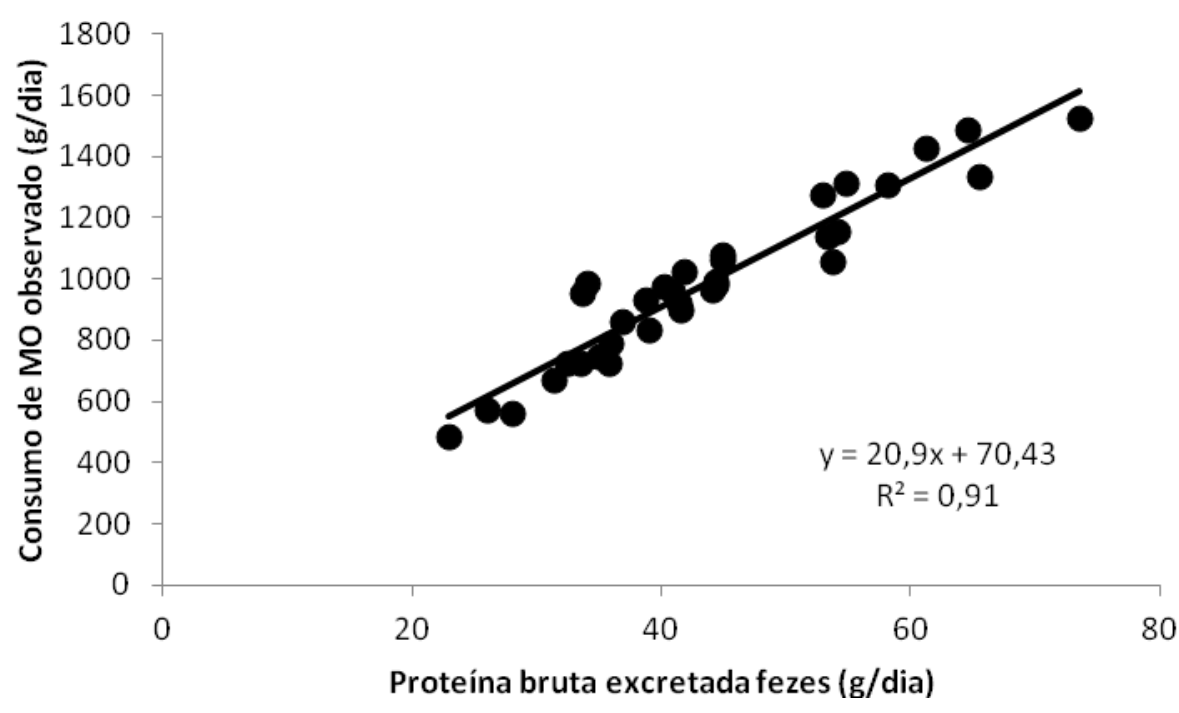

Figura 1. Estimativa do consumo diário de $\mathrm{MO}$ com base na excreção fecal diária de $\mathrm{PB}$ (PBf) em ovinos ingerindo grama missioneira gigante e amendoim forrageiro na proporção 75:25.

Tabela 3. Consumo de MO de forragem por cordeiros pastejando grama missioneira gigante com ou sem acesso a pastos de amendoim forrageiro por duas horas diárias e com duas alturas de entrada (alta ou baixa)

\begin{tabular}{|c|c|c|c|c|c|c|c|c|}
\hline & \multicolumn{2}{|c|}{ Sem acesso à leguminosa } & \multicolumn{2}{|c|}{ Com acesso à leguminosa } & \multirow[b]{2}{*}{ dpr } & \multicolumn{3}{|c|}{ Valor de $P$} \\
\hline & Alta & Baixa & Alta & Baixa & & Leg. & Alt. & $\begin{array}{c}\text { Leg. } \\
\times \\
\text { Alt. }\end{array}$ \\
\hline g/dia & 1010 & 1119 & 1202 & 1300 & 157,7 & 0,015 & 0,017 & 0,008 \\
\hline$\%$ do peso vivo & 3,45 & 3,58 & 4,14 & 4,18 & 0,552 & 0,017 & 0,738 & 0,865 \\
\hline $\mathrm{g} / \mathrm{kg} \mathrm{PV}^{0,75}$ & 80,2 & 84,5 & 95,8 & 98,5 & 11,22 & 0,018 & 0,487 & 0,868 \\
\hline
\end{tabular}

dpr= desvio-padrão residual; Leg.= efeito do acesso à leguminosa; Alt. $=$ efeito da altura de entrada; Leg. $\times$ Alt. $=$ efeito da interação acesso à leguminosa $\times$ altura de entrada.

\section{DISCUSSÃO}

A consistência na estimativa do consumo de MO com base na PBf, utilizando a equação gerada no presente trabalho, possibilitou o seu uso no experimento subsequente e demonstra que a confiabilidade dessas estimativas depende do uso de equações geradas com as mesmas espécies forrageiras a serem avaliadas em situação de pastejo. Isso pode ser explicado pelo fato de que, mesmo sendo o $\mathrm{N}$ excretado nas fezes predominantemente de origem metabólica, o qual é linearmente afetado pela ingestão diária de alimento (Kozloski et al., 2014), também existe uma fração do $\mathrm{N}$ fecal originado da proteína indigestível de origem alimentar (Vérité e Peyraud, 1989). Considerando que forragens com teores semelhantes de proteína indigestível podem proporcionar diferentes consumos voluntários de $\mathrm{MO}$, conclui-se que o uso generalizado de equações para estimativa do consumo com base em indicadores de índice fecal pode ser criticável.

Para confirmar a acurácia da estimativa proposta pela equação gerada neste trabalho, em comparação a dados de literatura, os consumos médios observados nos animais do presente estudo foram comparados de maneira descritiva com valores estimados a partir de equações publicadas por autores que trabalharam com pastos de clima tropical (Kozloski et al., 2014; Boval et al., 1996), sendo os resultados apresentados na Tabela 4. 
Pode-se observar que, pelas equações de Kozloski et al. (2014), as melhores estimativas foram aquelas que utilizaram os dados provenientes de avaliações com gramíneas tropicais mais leguminosas tropicais. Contudo, mesmo nessa situação, o consumo de MO ainda foi subestimado em 14\%. Quando se utilizou a equação de Boval et al. (1996), o consumo observado foi subestimado em $9 \%$.

Tabela 4. Consumo médio observado de MO (g/dia) por ovinos ingerindo grama missioneira gigante e amendoim forrageiro $(75: 25)$ e valores estimados com base em equações do próprio estudo ou em equações adaptadas da literatura

\begin{tabular}{ccccccc} 
& $\begin{array}{c}\text { Consumo } \\
\text { observado } \\
\text { MO }\end{array}$ & $\begin{array}{c}\text { Consumo estimado } \\
\mathrm{MO}^{1}\end{array}$ & \multicolumn{2}{c}{ Boval et al. (1996) } & \multicolumn{2}{c}{$\begin{array}{c}\text { Kozloski } \text { et al. } \\
\text { (2014) }\end{array}$} \\
\cline { 3 - 7 } & 984 & $\mathrm{Eq1}^{2}$ & $\mathrm{Eq}^{3}$ & Geral $^{4}$ & Trop $^{5}$ & Trop+leg $^{6}$ \\
\hline Média & 984 & 552 & 901 & 743 & 725 & 862 \\
\hline
\end{tabular}

${ }^{1}$ Equação originada do presente estudo: consumo de $\mathrm{MO}(\mathrm{g} / \mathrm{dia})=70,4+20,9 \times \mathrm{PBf}(\mathrm{g} / \mathrm{dia})$.

${ }^{2}$ Gerada de dados individuais: consumo de $\mathrm{MO}(\mathrm{g} / \mathrm{dia})=2,327+12,59 \times \mathrm{PBf}(\mathrm{g} / \mathrm{dia})$,

${ }^{3}$ Gerada de dados médios: consumo de $\mathrm{MO}(\mathrm{g} / \mathrm{dia})=0,667+20,63 \times \mathrm{PBf}(\mathrm{g} / \mathrm{dia})$.

${ }^{4} \mathrm{Geral}$ - gerada de experimentos com diferentes tipos de plantas e clima: consumo de MO (g/dia) $=356+55,4 \times \mathrm{Nf}^{*}$ $(\mathrm{g} / \mathrm{dia}) ; * \mathrm{Nf}=(\mathrm{Pbf} / 6,25)$.

${ }^{5}$ Trop - gerada de experimentos com gramíneas de clima tropical: consumo de MO (g/dia) $=132+85 \times \mathrm{Nf} *$ (g/dia); $* \mathrm{Nf}=(\mathrm{PBf} / 6,25)$

${ }^{6}$ Trop+leg - gerada de experimentos com mistura de gramíneas e leguminosas de clima tropical: consumo de MO $(\mathrm{g} / \mathrm{dia})=618+35 \times \mathrm{Nf} *(\mathrm{~g} / \mathrm{dia}) . * \mathrm{Nf}=(\mathrm{PBf} / 6,25)$.

No segundo experimento, a inexistência de diferença no consumo de forragem em função das alturas indica que, devido às condições de manejo impostas, os animais não sofreram restrições de ordem quantitativa ou qualitativa. Sabe-se que o aumento da altura do dossel em pastos de gramíneas é normalmente acompanhado de mudanças na relação folha:colmo, o que pode levar a alterações no valor nutritivo (Van Soest, 1994) e no consumo diário de forragem. Ou seja, com o aumento da idade de rebrota, tende-se a diminuir a relação folha:colmo, com reduções no consumo e na digestibilidade da MS (Valente et al., 2010; Gontijo Neto et al., 2006). Porém, em algumas espécies forrageiras, como parece ser o caso da grama missioneira gigante, a relação folha:colmo tende a não se modificar tão rapidamente quanto em outras, o que contribui para a manutenção de elevada proporção de folhas no estrato pastejado.

Nesse sentido, trabalhos que avaliaram a grama missioneira gigante citam proporções médias de folha:colmo na ordem de 2,3:1 (Lorenzoni et al., 2016); para alguns acessos dessa planta, a relação folha:colmo se manteve em torno de 1,5:1, mesmo quando a idade de rebrota chegou a 240 dias (Lajús et al., 2011). De acordo com Pinto et al. (1994), relações folha:colmo $\leq 1,0$ resultam em queda na qualidade da forragem. Dessa forma, os resultados observados no presente estudo vão ao encontro do descrito por outros autores (Carnevalli et al., 2001), os quais não observaram diferença no ganho de peso e no consumo de MS por ovinos em pastos de coastcross manejados em diferentes alturas. A explicação lógica para isso é o fato de a qualidade nutricional do pasto não ser função da altura "per se", mas da proporção folha:colmo, o que ocorre em razão de a qualidade da folha sofrer pequena alteração com o envelhecimento (Stabile et al., 2010). Além disso, deve-se considerar que os ovinos são animais bastante seletivos, o que reforça a ideia de que a forragem colhida em ambas as alturas de entrada foi constituída predominantemente por folhas.

O aumento de aproximadamente $20 \%$ no consumo dos animais com acesso ao pasto de amendoim forrageiro demonstra que o acesso ao pasto de leguminosa por duas horas diárias é suficiente para promover significativo incremento na ingestão diária de nutrientes por ovinos em pastos de clima tropical. O efeito da inclusão de leguminosas sobre a ingestão diária de forragem é relativamente bem descrito tanto em forrageiras de clima temperado (Rogers et al., 1979; Harris et al., 1998; Ribeiro-Filho et al., 2003; Niderkorn e Baumont, 2009), como de clima tropical (Lascano, 1994; Gonzáles et al., 1996). O maior consumo de leguminosas, em comparação a dietas compostas exclusivamente 
por gramíneas, deve-se principalmente a fatores ligados ao menor preenchimento ruminal devido à maior velocidade de degradação e ao menor tempo de retenção no rúmen (Steg et al., 1994; Niderkorn e Baumont, 2009). Nesse sentido, observa-se que o consumo total de MS aumenta de 10 a $25 \%$ quando leguminosas são adicionadas a dietas de animais ingerindo gramíneas de clima tropical ou temperado. Em trabalho realizado no mesmo local do presente estudo, novilhos pastejando capim- elefante anão com acesso a piquetes de amendoim forrageiro por seis horas diárias aumentaram em cerca de $12 \%$ o consumo diário de MS (Andrade et al., 2016). Além disso, foi verificado que o consumo de forragem não varia quando o acesso aos piquetes da leguminosa diminui de seis para duas horas diárias (Liz et al., 2014). Observa-se, portanto, que, assim como para bovinos, o acesso a piquetes exclusivos de leguminosas por períodos relativamente curtos (duas horas) pode constituir importante ferramenta de manejo em sistemas de produção de ovinos.

\section{CONCLUSÃO}

Em situações de oferta de forragem não restritiva, alturas pré-pastejo entre 25 e $35 \mathrm{~cm}$ não afetam o consumo de grama missioneira gigante por ovinos, o que demonstra boa flexibilidade de manejo dessa espécie forrageira. Além disso, o acesso a piquetes de amendoim forrageiro por duas horas diárias aumenta o consumo total de matéria seca de cordeiros pastejando essa gramínea.

\section{AGRADECIMENTOS}

O presente trabalho foi realizado com apoio da FAPESC/UDESC (PAP - 01/2016) e da Coordenação de Aperfeiçoamento de Pessoal de Nível Superior - Brasil (CAPES) - Código de Financiamento 001.

\section{REFERÊNCIAS}

AFNOR, A.F.D.N. Aliments des animaux. Paris, France: 1985.

ANDRADE, E.; ALMEIDA, E.X.; RAUPP, G.T.; MIGUEL, M.F. Herbage intake, methane emissions and animal performance of steers grazing dwarf elephant grass v. dwarf elephant grass and peanut pastures. Animal, p.1-5, 2016.
BARBERO, L.M.; CECATO, U.; LUGÃO, S.M.B. et al. Forage production and morphological components of coastcross pasture mixed with peanut forage. Rev. Bras. Zootec., v.38, p.788-795, 2009.

BOVAL, M.; PEYRAUD, J.L.; XANDE, A. et al. Evaluation d'indicateurs fécaux pour prédire la digestibilité et les quantités ingérées de Dichanthium sp par des bovins créoles. Ann. Zootech., v.45, p.121-134, 1996.

CARNEVALLI, R.A.; SILVA, S.C.; CARVALHO, C.A.B. et al. Desempenho de ovinos e respostas de pastagens de Coastcross submetidas a regimes de desfolha sob lotação contínua. Pesqui. Agropecu. Bras., v.36, p.919927, 2001.

CARVALHO, P.C.F.; KOZLOSKI, G.V.; RIBEIRO FILHO, H.M. et al. Avanços metodológicos na determinação do consumo de ruminantes em pastejo. Rev. Bras. Zootec., v.36, Supl. esp., p.151-170, 2007.

GONTIJO NETO, M.; EUCLIDES, V.P.B.; NASCIMENTO JÚNIOR, D. et al. Consumo e tempo diário de pastejo por novilhos Nelore em pastagem de capim-tanzânia sob diferentes ofertas de forragem. Rev. Bras. Zootec., v.35, p.60-66, 2006.

GONZÁLES, M.S.; NEURKVAN, L.M.; ROMERO, F. et al. Producción de leche en pasturas de Estrella Africana (Cynodon nlemfuensis) sólo y asociado con Arachis pintoy y Desmodium ovalifolium. Pasturas Trop., v.18, p.2-12, 1996.

HARRIS, S.L.; AULDIST, M.J.; CLARK, D.A.; JANSEN, E.B. Effects of white clover content in the diet on herbage intake, milk production and milk composition of New Zealand dairy cows housed indoors. J. Dairy Res., v.65, p.389-400, 1998.

KOZLOSKI, G.V.; OLIVEIRA, L.; POLI, C.H.E.C. et al. Faecal nitrogen excretion as an approach to estimate forage intake of wethers. $J$. Anim. Physiol. Anim. Nutr., v.98, p.659-666, 2014.

LAJÚS, C.R.; SCHEFFER-BASSO, S.M.; MIRANDA, M. et al. Morphophysiological characterization of giant missionary grass accessions. Rev. Bras. Zootec., v.40, p.23022307, 2011. 
LASCANO, C.E. Nutritive value and animal production of forage Arachis. In: (KERRIDGE, P.C.) Biology and agronomy of forage Arachis. Colombia: CIAT Cali, 1994. 221p.

LIZ, D.M.D.; RIBEIRO FILHO, H.M.N.; ANDRADE, E.A. et al. Herbage intake and animal performance of cattle grazing dwarf elaphant grass with two access times to a forage peanut area. Ciênc. Agrotecnol., v.38, p.607-614, 2014.

LORENZONI, I.G.; LUCCA, L.S.; SILVA, I.W. et al. Desempenho da grama missioneira gigante (Axonopus catharinensis valls) na região noroeste do rio grande do sul. Salão Conhec., v.2, 8p., 2016.

NIDERKORN, V.; BAUMONT, R. Associative effects between forages on feed intake and digestion in ruminants. Animal, v.3, p.951-960, 2009.

OFFICIAL methods of analysis. Arlington, Va.: AOAC International, 1995.

PINTO, J.C.; GOMIDE, J.A.; MAESTRI, M. Produção de matéria seca e relação folha:caule de gramíneas forrageiras tropicais, cultivadas em vasos, com duas doses de nitrogênio. Rev. Soc. Bras. Zootec., v.23, p.313-326, 1994.

RIBEIRO FILHO, H.M.N.; DELAGARDE, R.; PEYRAUD, J.L. Inclusion of white clover in strip-grazed perennial ryegrass swards: herbage intake and milk yield of dairy cows at different ages of sward regrowth. Anim. Sci.,v.77, p.499$510,2003$.

ROGERS, G.; PORTER, R.; ROBINSON, I. The utilization of perennial ryegrass and white clover by lactating dairy cows. Victoria, Australia: Dairy Research Institute, 1979.

STABILE, S.D.S.; SALAZAR, D.R.; JANK, L. et al. Características de produção e qualidade nutricional de genótipos de capim-colonião colhidos em três estádios de maturidade. Rev. Bras. Zootec., v.39, p.1418-1428, 2010.
STATISTICAL analysis system. Version 9.0. Cary: SAS Institute, 2004. 5135p SCHNAIDER, M.A.; RIBEIRO-FILHO, H.M.; KOZLOSKI, V. et al. Intake and digestion of wethers fed with dwarf elephant grass hay with or without the inclusion of peanut hay. Trop. Anim. Health Prod., v.46, p.975-980, 2014.

STEG, A.; STRAALEN, W.M. van; HINDLE, V.A. et al. Rumen degradation and intestinal digestion of grass and clover at two maturity levels during the season in dairy cows. Grass Forage Sci., v.49, p.78-390, 1994.

TCACENCO, F.A.; SOPRANO, E. Produtividade e qualidade da grama missioneira gigante [Axonopus jesuiticus (Araújo) Valls] submetida a vários intervalos de corte. Pasturas Trop., v.19, p.28-35, 1997.

VALENTE, B.S.M.; CÂNDIDO, M.J.D.; CUTRIM JÚNIOR, J.A.A. et al. Composição químico-bromatológica, digestibilidade e degradação in situ da dieta de ovinos em capimtanzânia sob três frequências de desfolhação. Brasília: Embrapa 2010. 8p.

VAN SOEST, P.J. Nutritional ecology of the ruminant. Ithaca: Cornell University Press, 1994. 479p.

VAN SOEST, P.V.; ROBERTSON, J.; LEWIS, B. Methods for dietary fiber, neutral detergent fiber, and nonstarch polysaccharides in relation to animal nutrition. J. Dairy Sci., v.74, p.35833597, 1991.

VÉRITÉ, R.; PEYRAUD, J.L. Protein: the PDI system. In: JARRIGE, R. (Ed.). Ruminant nutrition: recommended allowances and feed tables. Paris: John Libbey Eurotext, 1989. p.3347

WARAMIT, N.; MOORE, K.J.; FALES, S.L. Forage quality of native warm-season grasses in response to nitrogen fertilization and harvest date. Anim. Feed Sci. Technol., v.174, p.46-59, 2012. 